\title{
Developing true community care for the elderly mentally ill
}

\author{
M. T. Malcolm, Consultant Psychiatrist, Clatterbridge Hospital, Bebington, Wirral, \\ Merseyside L63 4JY
}

"If you are going there, you shouldn't start from here".

This advice to a traveller could be offered to those moving resources from institutional care of the elderly to true care in the home. While present plans concern the destination and mode of travel, less attention is paid to differences in the starting point. Health districts vary greatly in terms of numbers, movements and placements of their elderly populations. Numerical increases or decreases may be caused by migration of elderly people to traditional seaside retirement areas. A further attraction is the availability of nursing and residential homes in these belts. Such homes tend to multiply in a given area and draw in new residents from other districts leading to a disproportionately elderly population.

Large numbers of dependent elderly are now accommodated in homes 'in the community' rather than in long-stay hospitals as had often been the case in the past. Indeed some of the residents may have been transferred to a home after many years in hospital. The needs of elderly people recently arrived in their bungalow or nursing home, far from supporting relatives and neighbours, are all very different and may change rapidly. The result is that districts have very varied populations and are therefore starting their journeys from very different positions. To plan and to fund community care successfully, more than the absolute numbers of elderly are required. Although descriptions may be subjective and inexact, each district needs a descriptive account of its current provision for the elderly, whether it is appropriate or not, and a knowledge of the factors influencing these populations and provisions. Wirral is such a district.

'Peninsulas seem to evolve distinctive patterns' (The Rising Tide, 1982). How true this comment is for the Wirral Peninsular, an area of land 10 by 20 miles, lying between Liverpool and North Wales with a total population of 354,300 of whom $58,200(16.4 \%)$ are aged 65 and over, including 25,400 over 75 . The development of residential and nursing homes relies on the availability of potential residents, funds to pay fees and buildings suitable for conversion - few are purpose-built. There is an increasing number of elderly people: all that may be required is their 'agreement' to admission and the homes' acceptance of them. Need or suitability is not always essential.
If fees cannot be met, public funds have been made available, though the Secretary of State for Health (1989) questioned this use of public money when he wrote, "The rapid growth of residential and nursing home care has been unplanned and largely based on the availability of Social Security benefits". As regards suitable buildings, Wirral has long been an up-market dormitory area for Liverpool and still has many large 19th century houses, some enclosed in their own parks. Typical are Egerton Park and Rock Park, the latter evocatively described by Hubbard (1978) as "a private residential estate enclosed within lodge gates, 1836-7. This attractive sylvan suburb is picturesquely planned with a serpentine looped driveway, has frontage to the esplanade and river ...". Nathanial Hawthorne, the American author, lived in one of the "pretty residences". The parks already have eight homes offering 174 beds and with more planned, will be reminiscent of the villa system which existed in some county mental hospitals. Hawthorne's novel The Old Home was partly inspired by his spell in Merseyside and when on his sick bed in America he said "If I could go to England I think that the sea and the sight of the Old Home would set me right" (Hope, 1988). Sadly his house is not one of the nursing homes!

The above is just one example of the large-scale developments of various types of residential homes in the Wirral. Ninety nursing homes exist offering 2,595 beds and although there is a variable vacancy factor, perhaps $7 \%$, an additional 40 such homes with 1,500 beds are proposed. Residential homes provide a further 1,470 beds, with many more planned. The local authority has about 1,500 wardened beds and 904 elderly person's home beds, though the latter are due to be sold. Hospital, geriatric and other longer stay facilities offer about 600 beds, ESMI nearly 100 beds. Boarding out schemes, hotels and guest houses for the long-stay elderly, lodgings, and homes with less than four beds for the elderly probably contribute at least 500 places, perhaps many more. Private housing associations, with or without wardens, may well have over 1,000 beds. These are closer to "own home" facilities. The overall number of beds is approaching 10,000 , i.e. $17 \%$ of the elderly population are in various homes. This is 
the numerical equivalent to half a dozen traditional mental hospitals, all in one relatively small area.

Other selected areas of Britain have seen similar phenomenal growth. Ten years ago there were only 7,000 elderly patients in private homes at public expense (Royal College of Psychiatrists, 1987). The usually high standards of care combined with the constantly increasing number of beds available in Wirral homes have led to an influx of patients from various parts of the country and from contracting local mental hospitals. Discharges from the latter, if declared, would bring a dowry which could fund NHS community provisions. Nursing homes' fees in the Wirral may be less than in the south of England. An advertisement in a national periodical pictured a delightful historic building with an invitation to apply to a south coast address; confused residents may not know they will be living in Merseyside!

The presence of so many vacant beds can facilitate the rapid discharge of patients, though by whom and to where and under what influences is open to discussion. Although good performance indicators such as throughput of patients can be achieved, quality of care, especially in the community, may be adversely affected by disproportionate demands. The Royal College of Psychiatrists' report (1987) warned of such dangers and the Wirral Community Health Council's report of the same year expressed anxiety at the tremendous increase in private homes. Reports of local Council debates spoke of these developments as "near to reaching saturation point". Powers to restrict developments in specific areas were limited. Indeed with suggested guidelines of up to $20 \%$ of any street being given over to "institutional" use an area could become a "geriatric ghetto". Wattis (1988) described the Mersey as one of the two Regions least well covered by psychiatric services to old people. Wirral is a poor relation even in Merseyside with less than 100 ESMI beds and 25-50 day places.

Griffiths proposes to reduce reliance on nursing home and residential home places, yet on the Wirral thousands more beds are planned. While current proposals continue to fund existing residents it seems likely there will be fewer such residents in the future. In spite of this, chains of nursing homes are still a popular investment "Brewers and hoteliers falling over one another to get into the market.... Lancashire brewer, splashed out $£ 21.5 \mathrm{~m}$ for eleven homes at the top end of the market last year, paying a top whack of $£ 48,000$ a bedroom. Ladbroke netted an impressive $£ 42.6 \mathrm{~m}$ for its homes sold to another
(Geordie) brewer.... Rising staff costs eat into profits... Local authorities often (sic) have demanding standards for staffing levels..." (Investors Chronicle, 1989).

In seeking funds for community care for the elderly, Wirral must ensure that, "Account will be taken of ... growth due to demographic and other factors" (Caring for People, summary, 1989). Will these be based on the crude total of 58,200 or on the 10,000 currently perceived as needing various levels of care? Will Social Service departments from different parts of the country buy places in Wirral's existing nursing and residential homes? If they do, will medical and social back-up services be adequate and who will pay for them?

If Wirral has a service based on its own elderly residents, what will happen to the existing massive investment, to staff of different professions and grades and indeed, our Victorian and Edwardian building stock? Is it relevant that Victorian hospital buildings are now back in fashion and refurbishment is to be supported? Will the community care pendulum swing back, for community care done properly is known not to be a cheap option. We are not all starting the Griffiths changes from the same place. Unless qualitative as well as quantitative factors are considered, Wirral may regret the influx of elderly and, like country asylums or Hong Kong, look for some form of repatriation.

\section{References}

Department of Health (1989) Caring for People: Community Care in the Next Decade and Beyond. Summary. London: HMSO.

HoPE, M. (1988) The Forgotten Shores. Birkenhead: Countervise Ltd.

HuBBard, E. (1978) Outer Birkenhead. In The Buildings of England (Pevsner, N. \& Hubbard, E.). Harmondsworth: Penguin.

Investors Chronicle (1989) Nursing home profits squeezed. 19 May 1989.

National Health Service Health Advisory Service (1982) The Rising Tide. London: DHSS.

Royal College of PSYCHIATRISTs (1987) Private care for the elderly mentally ill. Bulletin of the Royal College of Psychiatrists, 11, 278-282.

SeCRETARY Of State fOR Health (1989) Health Notice. H.N.(89) 18, July 1989.

WaTTIS, J. P. (1988) Geographical variations in the provision of psychiatric services for old people. Age and Ageing, 17, 171-180. 